\title{
APPLICATION OF INFORMATION TECHNOLOGIES AND INTERACTIVE TOOLS FOR IMPROVING EDUCATIONAL QUALITY
}

Krasimira Georgieva $^{1}$, Vanya Stoykova ${ }^{2}$, Nevena Ivanova $^{3}$, Emilia Dimova $^{4}$

\begin{abstract}
Absract: The rapid development of science, technology, and information technologies in various sectors of the economy imposes increased requirements and expectations in the preparation of engineering professionals in higher education. In recent years, there have been some difficulties in engineering and technology training related to the assimilation of the methodology for constructive thinking, the development of clear and precise knowledge structuring, improvement of the ability of expressing thoughts, and graphical presentation of information.

This article presents some applications and best practices in the use of e-learning systems, interactive boards, and accessories. The application of active teaching methods and use of information technologies with interactive tools, providing active involvement of the students in training, leads to considerable interest and improvement in the quality of teaching and learning.
\end{abstract}

UDC Classification: 004.9, DOI: http://dx.doi.org/10.12955/cbup.v3.640

Keywords: interactive presentation systems, interactive whiteboard, document camera, digital marker, digital generation

\section{Introduction}

The rapid development of science, technology, and information technologies in various sectors of the economy requires increased demands and expectations in the preparation of engineering professionals in higher education. The changed conditions suggest adequate change in the organization, methods, and means of technological education. Technological training that forms technological culture and qualities has the basic tasks of acquiring knowledge, skills, and attitude that contribute the development of personality, intelligence, and creative direction for successful students' self-realization (Bozhkova, 2008).

The technological activities can be realized through the following approaches:

- Research activities, including research, compare, synthesis and summarisation information, theoretical research, experimentation, observation, analysis and evaluation. Some of these activities are included in the acquisition of scientific degree "doctor";

- Practical activities, including reflection, analysis, design, construction, elaboration, development and operation of real objects and technological processes. Training associated with the practice is the main pedagogical principle in preparing engineers with Bachelor's Degree and Master's Degree.

The engineering and technological education is related to the absorption of the methodology for constructive thinking, development of the ability to express thoughts and graphical presentation of information, development of clear and precise structuring of knowledge using the database, and development of the ability to work in a team environment.

In recent years, the students have difficulties in spatial thoughts creation and restoration of objects, plains, and surfaces and display them graphically. This affects, subsequently, in using different design methods for displaying objects, components, assemblies, and devices in accordance with the Standards

\footnotetext{
${ }^{1}$ Krasimira Georgieva, Trakia university - Stara Zagora, Faculty "Technics and technologies" of Yambol, Bulgaria, kr.g.georgieva@gmail.com

${ }^{2}$ Vanya Stoykova, Trakia university - Stara Zagora, Faculty "Technics and technologies" of Yambol, Bulgaria, vdstoykova@gmail.com

${ }^{3}$ Nevena Ivanova, Trakia university - Stara Zagora, Faculty “Technics and technologies” of Yambol, Bulgaria, nevena_venci@abv.bg

${ }^{4}$ Emiliya Dimova, Trakia university - Stara Zagora, Faculty "Technics and technologies” of Yambol, Bulgaria, em.d.dimova@gmail.com
} 
(BDS, ISO, etc.) and basic norms of interchangeability. This requires a search for new opportunities for training and learning using active methods and forms of teaching through the application of information technologies with interactive tools to ensure full participation of students in the learning process.

The purpose of this report was to present the possibilities of modern technical tools and electronic learning environments sutable for effective teaching, as well as some good practices in the students' preparation at Faculty "Technics and Technology" of Trakia University of Stara Zagora.

\section{Exposure}

\section{Use of e-learning system and training on technical subjects}

Over 105 electronic modules and complete courses have been developed and administered at Trakia University of Stara Zagora through Project BG-051 PO001-4.3.04-0026 "Development of Center for electronic and distance learning forms at Trakia university," funded by the Operational Programme "Human Resources Development."

The subjects forming a part of project - engineering preparation are: "Engineering Graphics" and "Machine Elements," which have been developed in electronic format and included in the university system for e-learning, based on Moodle platform. The courses are well-structured and contain teaching units (text materials in .pdf format, presentations, and video materials) corresponding to the themes of the theoretical course and practical exercises (Figure 1). There are tests for self-assessment and evaluation of knowledge on the subject. Knowledge gained by them allows for graphical representation of information and development of project-construction skills related to imagination, the ability to present objects and devices in perspective. The students have the opportunities in parallel with traditional learning to use the resources from distance training course for further development and reinforcement of their knowledge on the subject. The practical training on "Engineering Graphics" and "Machine Elements" is associated with elaborating sketches and drawings, so the material is designed with multiple images showing step-by-step stages of building the task using different methods of design in a data block (Georgieva \& Georgieva, 2015). The students have opportunities multiple times follow the algorithm of work on the assignments or to return "step" back instruction on the task.

The main advantage is the personalization of learning according to specific needs of individual students, i.e. they can choose the time, the place, and the pace of learning from the published teaching materials. The distance online training and video materials are unquestionably preferred by students today due to their "affection" for the modern information and communication technologies, and also because of their ability to overcome problems related to the geographical location of learners and the resulting financial problems.

That is why the participation of students in e-course is active as it improves the quality of training on the subject "Engineering Graphics," and it has increased the average grade on the semester exams for "Engineering Graphics" by $10.5 \%$. This gives us grounds to deepen and further expand the possibilities of using e-learning systems and interactive tools.

However, the training of technical personnel cannot be held entirely through distance system (Vuchinska \& Naumov, 2013). In fact, it is more appropriate for the technical personnel to participate in a mixed type of learning (blended learning) that is characterized by upgrading, or "splicing," integration of various information and communication technologies in a traditional educational context. 
CBU INTERNATIONAL CONFERENCE ON INNOVATION, TECHNOLOGY TRANSFER AND EDUCATION

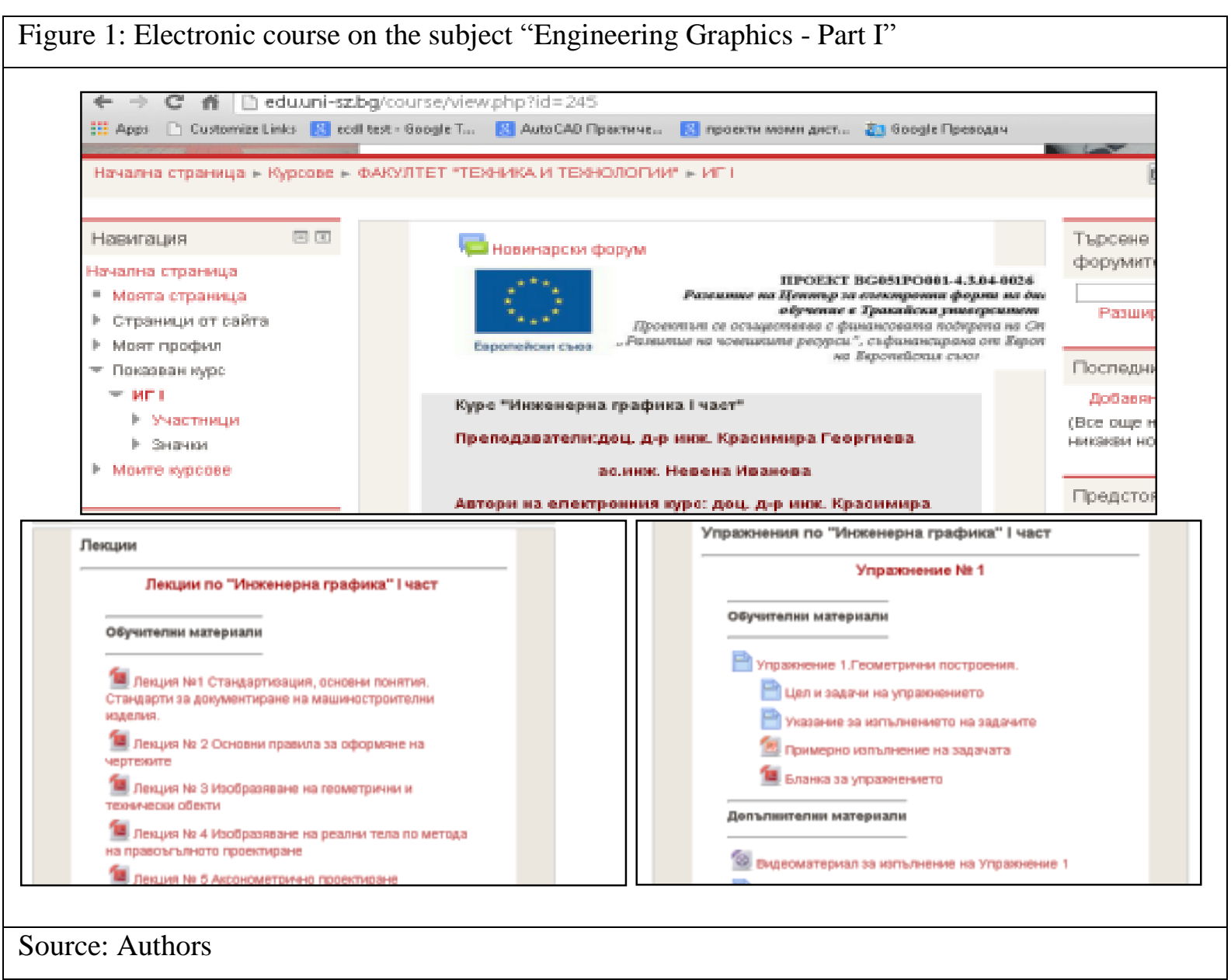

\section{Opportunities of advanced interactive technical tools}

Interactive presentation systems (IPS) are gradually becoming the most important element in an interactive classroom and auditorium of the future (Figure 2). They have indisputable opportunities in terms of visualization of curricula, increase in attractiveness, dynamism, and informativeness of classes. Other modern technical training tools (document camera, tablets for the students and the teacher, operational control systems - Classroom Performance System, etc.) can be integrated to the IPS (Figure 2). The implementation of the aforementioned can motivate current and prospective students to more actively and fully participate in lectures and seminars.

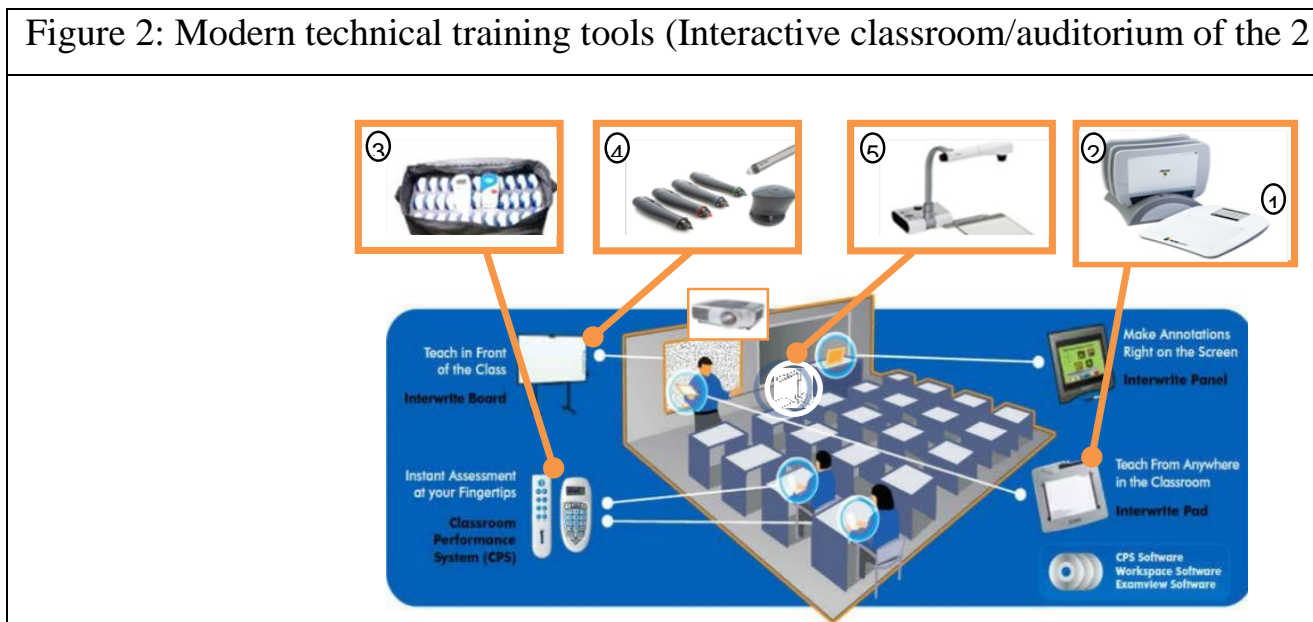

Source: Authors 


\section{Interactive presentation systems}

A part of all interactive boards software consists of tools for writing notes and annotations on presentation materials and for adding figures (including arrow and graphical objects).

On the image (2-D drawing or 3-D model), presented on the interactive white board (IWB), the teacher can enter additional clarifications by tools (e.g. Freehand Pen, Shapes, Text, Line, etc.) during the lecture or seminar. For better visualization, the teacher can use the zooming tool (Zoom), and with a view to active participation of learners, he/she can use the hide tools or visualization tools (eg. Curtain, Layer, etc.), even focusing (Spotlight) on certain parts of the learning content. A good and useful practice is related to the possibility of representing on the interactive board training video films, for example, on subject "Machine Elements" that requires study of the types of cog gears and their operation in a reducer.

In the pause the lecturer can put notes and annotations on the image and explain the presented mechanisms, then to continue with the subsequent footage of the video (Figure 3). The tool for video recording from the software IWB (InterWrite Workspace, Interactive Mode) can be started in advance to record all notes from the video and footage, including the lecturer's comments in avi or similar audio-video format.

\begin{tabular}{|l|l|l|l|}
\hline Figure 3: Comments on the training video film on subject "Machine Elements" \\
\hline
\end{tabular}

Most IWBs have, as a part of their software, drawing tools (e.g., Clasus, IQ Board, InterWrite DualBoard - Ruler, Triangle, Compass, Protractor), which can be used to construct objects in the classes (e.g., on the subject of "Engineering Graphics"). The teacher can draw by using the stylus on the IWB with the drawing tools from the IWB. However, a successful IWB application also requires the students to have the necessary knowledge and skills. Otherwise, their learning would take a lot of time, and it would have an adverse effect on their "dynamic" digital learning.

It is desirable not to lose time to routine activities during the lecture, thus it is possible for the teacher to prepare parts of the drawing in advance (in .gwb file). During the lesson, his/her only tasks are to project the drawing onto the IWB, finish it by using instruments from the IWB and the stylus, and explain the algorithm for solving the specific problem.

IWBs have instruments to record the contents on the board in a video file (Record), through which all actions (e.g. construction of an object's projections, Figure 3) or the lecturer's guidance can be saved in avi or similar format. The recording can take place during the lesson and the created files can be published in the subject e-course. They can assist students in their self-training and review.

The teacher can also conduct the lesson in a traditional way. For this purpose, the teacher can use additional color electronic markers and a special "eraser" to delete (Figure 2-4, eBeam Capture Pack). They are available options in some models of IWBs. In this case, the system operates as a conventional whiteboard (i.e. a projector is not needed), but there is still a option of recording the 
content of the board on the computer in audio-video file. The content of IWB can be shared through the students' computers in the same classroom or in a remote classroom.

Moreover, the major convenience for the teacher is that he/she can still conduct the teaching in a traditional way, and the system does not use a projector. However, the aforementioned case does not allow an advance preparation for the parts of the image or drawing, which could save some time.

On the other hand, the colored electronic markers work more slowly than the stylus (in some models IWB), and the image quality is not very good.

In Figure 3b, other opportunities to use the IWB at construction objects are presented. For instance, the third projection can be perceived by specifying the detail of two other projections. Aside from the IWB tools, the teacher can also use CAD system or any other graphic system (e.g. Microsoft Visio) to show the projections as well. Hence, the teacher can prepare the two projections in advance, and then introduces the methodology of constructing the third projection right in front of the students, using the stylus and drawing tools of the respective software. All of the lecturer's inputs can be recorded in avi format or analogy format. Students can view the published video files during their self-training.

In this case, we can regard higher accuracy of the construction objects and the image quality as some of the advantages compared to the above approaches. On the contrary, we can expect that the attention and comprehension of students in the digital generation may vary, based on the software, not as a result of the teaching methods on the subject of "Engineering Graphics."

\section{Document camera}

Another contemporary technical educational tool that we can integrate with IWB or use separately is a document camera (DC) (Figure 4). It allows for real-time object presentation on a normal or interactive whiteboard or screen with high quality and speed. We can use the device to create pictures or video of real objects and text. Some models are fully integrated with software and hardware of IWB. DC can be used for visualization of static and dynamic objects for experimental demonstration, zoom of images, and presentation on IWB objects viewed under a microscope. All of the possibilities of DC above can justify its application, e.g. in the course of "Engineering Graphics," because training visualization is of great importance for successful learning.

Document camera provides one of the easiest and fastest ways to integrate technologies in education. It is an amazing tool that allows students to work in a dynamic and interactive classroom. It can be used to actively engage students in the learning process. The teacher does not need to have special skills to use DC. The camera can be connected to the projector via a computer or directly to the projector, and it can record images placed in front of the camera in graphic (eg. .jpg) files or video files in its memory.

DC allows the projection to the audience (on screen or IWB), projection of printed documents (e.g. standards, periodicals, textbooks, drawings, documents, forms, specifications, etc.) without the need to scan and prepare them in advance. The teacher can present materials to the audience in real-time, photograph, and save them. They become a part of the materials for training and self-study (including presentations or video files).

The teacher has a possibility of using DC (without a computer), connecting to the projector, writing and explaining formulae or drawings (Figure 4-1, 4-2). Essentially, the lecturer writes or draws on a blank sheet of paper, pre-prepared template, or part of a drawing paper, placed in front of the camera. The image is displayed on the board with sufficient size (Figure 4-3). Most DC models, have a built-in microphone, and there is an opportunity to record the images and lecturer's explanations in audiovideo file onto the DC memory. The teacher can then publish these files through the university e- 
learning system under the subjects' blogs, clouds, etc.. According to our research, video clips are students' most preferred modern way of presenting educational content.

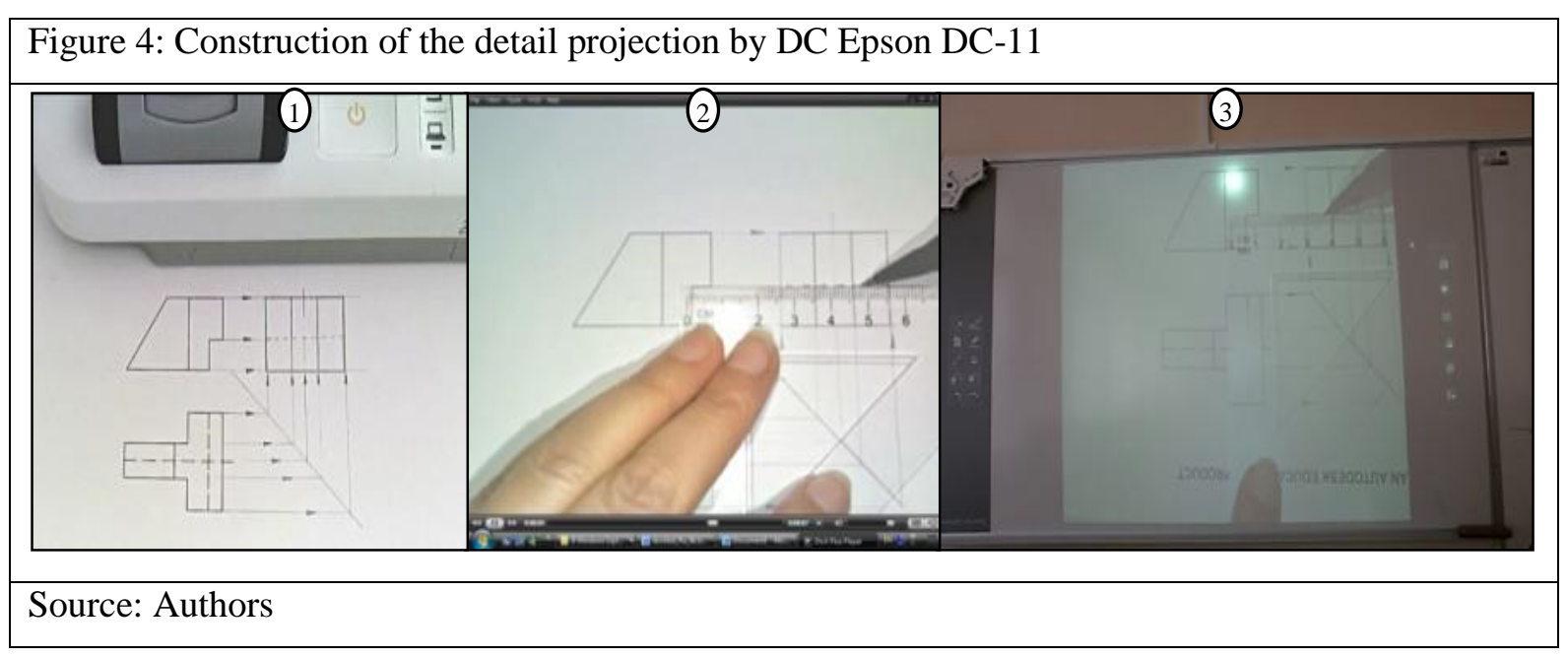

Another opportunity to demonstrate and study is the possibility to place real objects or photographs in front of the DC. Presented real object on IWB (grape leaves, Figure 5a) can be graphically processed as a 2-D image in order to analyze the colors (IMHIST function of Image Processing Toolbox in MATLAB, Figure 5b). The diagram shows the distribution of pixel values in the color bar of the image. There are $\boldsymbol{n}$ number of equally-spaced regions, each of them representing a range of color values. The teacher can calculate the number of pixels in each of these intervals and change the brightness of the image to determine its content. Various surfaces have different coefficients of reflection. The manager of the system (including IWB, DC, and computer) can expand it, allowing scientific research for students and PhD students. In addition, they can also install software programs on the computer for a visual system. Figure 5 illustrates the possibility in studying and investigating the diseases of a grapevine. The Faculty of Technics and technologies has developed a scientific project for integrating that visual system with an expert system for automatic diagnosis of diseases of plants, based on color changes by the subsystem visual perception in the vineyards.

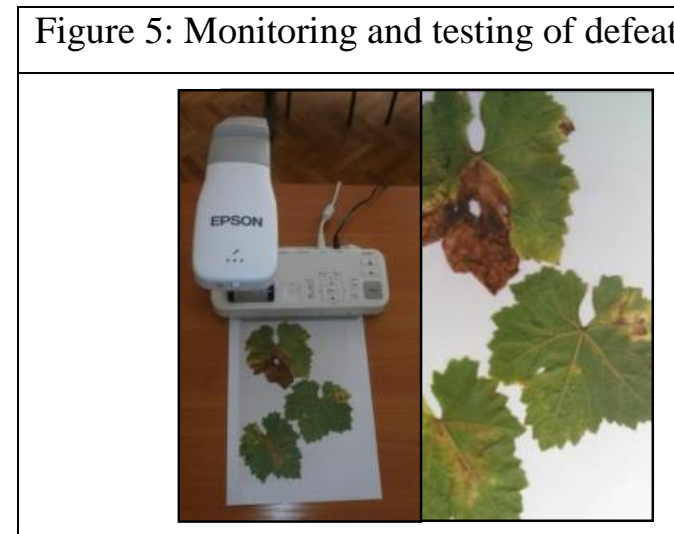

(a)

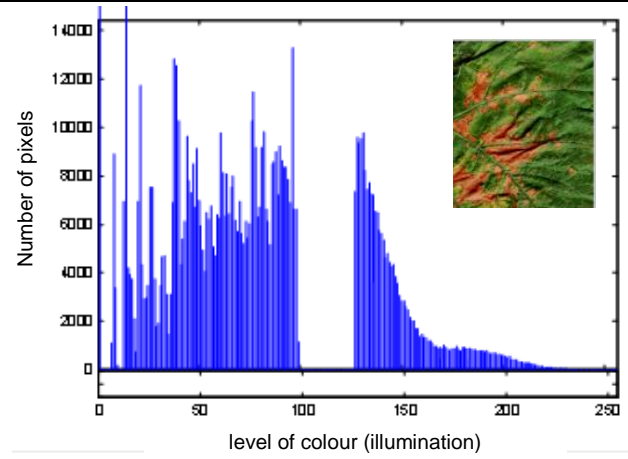

(b)

Source: Authors

This study can be stored as a part of a presentation or as an audio-video file using the appropriate tools, published through the university's e-learning system, and, subsequently, used during classes or self-training sessions for students. The above options can be used to support the technological preparation of students on the course "Mechanical Technology in Agriculture." 
All the above options are associated with the application of DC and IWB, and they can provide assistance for engineering technological training at universities.

\section{Conclusion}

The training materials related to the theoretical and practical preparation on the subject and control of knowledge can be provided with the possibilities of making e-learning system more accessible, attractive, and interesting for students in today's digital generation.

The high level of visualization that the teacher achieves through IWB and DC enables preparation of the learning content in the most appropriate way for students with visual-kinetic style of learning. More importantly, the interactivity leads to their active participation during the classes.

IWB and their additional devices allow the creation of video materials and their publication on the university e-learning systems as well as through the preferred means of today's students, such as social networks, blogs, and clouds.

\section{References}

Bozhkova, E. (2008). Praxeological approach in technological education. Southwest University. Retreived from, http://www. Sustz.com/Proceeding08/papers/Bozhkova_Emilia.pdf

Georgieva K., \& Georgieva, N. (2015, February-March). Comparative analysis of training engineering students on basic graphic and constructive skills. IV International Internet Conference "Problems of quality of graphic preparation".

Vuchinska, S., \& Naumov, V. (2013). Contemporary possibilities of teaching Applied Geometry and Engineering Graphic through distance training, Scientific papers of Rousse university, 52(4). 